\title{
Do culturalismo conservador à crítica da mídia: questões de comunicação no pensamento de Jessé Souza ${ }^{1}$
}

\author{
Márcio Serelle \\ Professor doutor dos programas de Pós- \\ Graduação em Comunicação Social e em \\ Letras, da Pontifícia Universidade Católica \\ de Minas Gerais (PUC Minas), com pós- \\ doutorado na University of Queensland, \\ Austrália. Pesquisador do CNPq. \\ E-mail: marcio.serelle@gmail.com.
}

Resumo: Este artigo objetiva debater questões comunicacionais presentes na obra de Jessé Souza que se referem à contribuição da mídia para propagação e consolidação do que o sociólogo denomina "culturalismo conservador". Essa expressão designa criticamente o pensamento social brasileiro que forjou um mito da brasilidade definido a partir de traços como miscigenação, emotividade e confiança interpessoal. A afirmação desse imaginário resultou na escamoteação de conflitos raciais e de classe e na ativação de um contraponto estadunidense idealizado, que afirma nossa inferioridade como povo e nação. Pretende-se, neste artigo, ressaltar a complexidade das interações midiáticas no processo de propagação e consolidação dessa ideia-força. Objetiva-se refletir sobre o papel das instâncias de sociabilidade na produção de sentido e os aspectos assimétricos da mediação. $O$ intuito é articular dois campos disciplinares para proposição de questões que facultem uma crítica social mais integral.

Palavras-chave: culturalismo conservador, crítica midiática, Jessé Souza -sociólogo brasileiro.

Del culturalismo conservador a la crítica de los medios: cuestiones de comunicación en la obra de Jessé Souza

Resumen: Este artículo aborda los temas de la comunicación presentes en los estudios de Jessé Souza que se refieren a la contribución de los medios a la propagación y consolidación de lo que el sociólogo llama "culturalismo conservador". La expresión designa críticamente el pensamiento social brasileño que crea un mito brasileño que se define a partir de rasgos como el mestizaje, la emocionalidad y la confianza interpersonal. Tal imaginario dio como resultado la ocultación de conflictos sociales y la activación de un contrapunto idealizado de los Estados Unidos que afirma nuestra inferioridad como nación. En este artículo se pretende resaltar la complejidad de las interacciones mediáticas en el proceso de propagación y consolidación de esta idea fuerza. Su objetivo es reflexionar sobre el papel de las instancias de sociabilidad en la producción de sentido y los aspectos asimétricos de la mediación. La intención es articular dos campos disciplinares para proponer preguntas que aporten una crítica social más integral.

Palabras clave: culturalismo conservador, crítica de los medios, Jessé Souza - sociólogo brasileño.

From conservative culturalism to media criticism: communication issues in the work of Jessé Souza

Abstract: This article discusses communicational issues regarding the role of the media in disseminating and consolidating the "conservative culturalism" present in the work of Jessé Souza. Coined by Souza, the expression critically refers to the Brazilian social thought that forged the myth of Brazilianness, defined by aspects such as miscegenation, emotionality, and interpersonal trust. Such imaginary both concealed social conflicts and set an idealized American counterpoint that affirms our inferiority as nation. In this sense, this article aims to highlight the complexity of media interactions in the process of propagation and consolidation of this idée-force, discussing the asymmetric aspects of mediation and the role of sociability instances in producing meaning. With that, the ultimate goal of this work is to articulate two disciplinary fields for proposing questions that will provide a more complete social critique. 
Jessé Souza consolidou-se, desde a publicação de $A$ ralé brasileira, em 2009, como sociólogo de intervenção pela interpretação que tem feito da realidade brasileira no século XXI, marcada pela passagem da ralé aos "batalhadores brasileiros" (Souza, 2012), pelo refluxo dessa transição e pelo impeachment de Dilma Rousseff. O termo intervenção enfatiza, aqui, tanto a combatividade das ideias como a disposição para alterar a realidade social. O projeto de Jessé Souza é abrir o pensamento acadêmico ao leitor não iniciado, pois o conhecimento deve ser "arma de combate" (Souza, 2015, p. 13) para o cidadão geral. O que caracteriza sua escrita, portanto, além da dicção empenhada e sem eufemismos, é a dissertação acessível.

Na leitura alternativa e arguta que faz do pensamento social brasileiro, Jessé Souza critica o que denomina culturalismo conservador, chave que explica a nação por meio de um mito de brasilidade fundamentado em aspectos como corporeidade, sensualidade, emotividade, miscigenação, confiança interpessoal e patrimonialismo. A tese, desenvolvida por Souza pelo menos desde A modernização seletiva (Souza, 2000), encontra-se, de acordo com o próprio autor, melhor acabada em A tolice da inteligência brasileira (Souza, 2015). Nessa revisão, Jessé Souza aponta que essas características, assimiladas como singulares ao brasileiro, resultaram, por um lado, no escamoteamento de conflitos sociais; por outro, na ativação de um contraponto, frequentemente idealizado em um "caráter" estadunidense, que evidencia nossa ocidentalidade incompleta e nossa inferioridade como povo e nação, isto é, nosso viralatismo.

A ênfase que o pensamento social deu ao patrimonialismo, por sua vez, segundo Souza, demonizou o Estado, visto como irremediavelmente ineficiente, corrupto e fisiologista, e valorizou o mercado (meritocrático e de razão técnica), sedimentando nosso liberalismo hegemônico e preparando terreno para o avanço neoliberal de hoje. A racionalidade neoliberal, entendida por Dardot e Laval (2016, p. 17) "como a generalização da concorrência como norma de conduta e da empresa como modelo de subjetivação", está sendo gestada de modo global desde a década de 1930. Podemos inferir que o culturalismo conservador contribuiu localmente com essa racionalidade ao, entre outros aspectos, negar entre nós a possibilidade de que o Estado possa atuar para o bem comum, produzindo e distribuindo riqueza.

O culturalismo conservador é, para Souza (2015, p. 31), uma "ideia-força", definida como "ideia articulada a interesses poderosos que permite mascará-los e justificá-los". Essa ideia-força foi concebida ensaisticamente pelo pensamento social brasileiro, legitimada como ciência no meio acadêmico e vulgarizada pela mídia. A crítica de Jessé Souza, devido à própria formação do autor, é mais circunscrita ao campo das ciências sociais e pode ser articulada aos estudos de comunicação para discussão acerca do processo de naturalização midiática e cotidiana do mito da brasilidade. Embora seja evidente que os meios de comunicação e suas narrativas estão implicados na constituição desse imaginário, esse é um processo complexo, pois não é monolítico nem linear. Isso não quer dizer que os significados dominantes veiculados pelas mídias também dominantes não possuem capacidade de penetração. No entanto, é preciso considerar os aspectos da mediação nas relações entre mídias e audiências, ainda que, como pontua Roger Silverstone (2002, p. 762, tradução nossa), o processo seja assimétrico, pois "o poder de trabalhar com ou contra os significados dominantes ou profundamente sedimentados que a mídia fornece está distribuído de forma desigual entre sociedades ou mesmo dentro de uma mesma sociedade".

Demanda-se, assim, compreender melhor os termos da aderência dos significados dominantes no cotidiano. Ou, ainda, por que, num país como o Brasil, cuja mídia é controlada por poucos grupos de alcance nacional regulados pelo pensamento liberal hegemônico, determinados significados aderem em certas regiões e em outras, são rechaçados.

Este artigo privilegia uma leitura comunicacional do pensamento de Jessé Souza com o intuito de articular competências entre os campos da sociologia e da comunicação para a crítica social mais integral. $\mathrm{O}$ texto divide-se em três partes, além desta introdução e das considerações finais. Inicialmente, apresenta-se síntese da tese do culturalismo conservador, em que a vertente predominante da interpretação 
do Brasil fixa-nos como sociedade pré-moderna; na segunda parte, levantam-se aspectos da obra de Jessé Souza que permitem compreender o pensamento do autor sobre os processos comunicativos e sobre como as mídias consolidam a ideia-força. $\mathrm{Na}$ terceira, abrem-se questões acerca das perspectivas de comunicação destacadas e colocam-se em relevo pontos para o desenvolvimento de uma crítica de mídia que, ciente da autonomia dos sujeitos, considere tanto a disputa hegemônica nos meios, como as instâncias de sociabilidade que envolvem os receptores.

\section{Culturalismo conservador}

De acordo com a tese do culturalismo conservador, parte do pensamento social e político brasileiro foi responsável pela criação de um "mito de brasilidade" que nos apresenta como predominantemente festivos, corpóreos e sexualmente aflorados, afetivos e personalistas. "Em resumo, somos o povo da 'emocionalidade' e da 'espontaneidade' enquanto oposição à racionalidade fria e ao cálculo que caracterizaria supostamente as nações avançadas do centro da modernidade" (Souza, 2018b, p. 35).

Como reconhece Souza, os mitos modernos - ou o que ele chama, a partir de Charles Taylor (2004), de imaginários sociais - são fundamentais para a construção de sentimentos de pertencimento e formação de cidadania. A crítica a eles, no entanto, é necessária para mudá-los e questioná-los quanto às "fantasias compensatórias" que propõem.

No caso do mito de brasilidade, há, segundo Souza, muitos aspectos socialmente danosos, como o encobrimento de conflitos de classe, a assunção de nossa insuficiência ocidental e a afirmação do outro estadunidense, a condenação do Estado e o elogio do mercado, conforme a racionalidade neoliberal. Essa não é uma chave de leitura cultural exclusivamente brasileira, mas, como analisei em outro texto (Serelle, 2018), refere-se ao imaginário de um Sul global, tido como culturalmente inferior em comparação ao Norte global, protestante ascético. Para Souza, essa foi uma forma de conceber um "racismo implícito", fundamentado em "estoque cultural", que "passa a substituir o racismo aberto do fenótipo e da cor da pele exercendo, no entanto, a mesma função explicativa de um racismo ontológico" (Souza, 2018b, p. 16).

Jessé Souza rastreia a formação desse mito a partir de Gilberto Freyre e de Sérgio Buarque de Holanda. Em Gilberto Freyre (1990), há o que Souza (2015, p. 30) descreve como a tese do "mestiço is beautiful", que possibilitou interpretar nossa miscigenação como elemento positivo de integração. "Foi Freyre, portanto, quem construiu o 'vínculo afetivo' do brasileiro como ideia de Brasil, em alguma medida, pelo menos positiva, com a qual a nação e seus indivíduos podiam se identificar e autolegitimar" (Souza, 2015, p. 30). A miscigenação atuaria, no encontro de raças, como ponto ativador de solidariedade social, em que diferenças eram amainadas ao mesmo tempo em que se valorizavam, em nosso povo, ideias como as de generosidade, hospitalidade e "calor humano".

O pensamento de Sérgio Buarque de Holanda (1995), por sua vez, é espelho invertido das ideias de Freyre. Em Holanda, os aspectos de cordialidade do brasileiro, com predomínio dos "contatos primários", conduzidos por laços afetivos e familiares, desembocariam em um desequilíbrio social, com a proliferação das práticas patrimonialistas no Estado. Para Holanda (1995), funcionários formados em ambiente como esse não tinham discernimento acerca das fronteiras entre o público e o privado, o que desencadeia o patrimonialismo, caracterizado pela confusão entre gestão pública e questões particulares.

No Brasil, pode dizer-se, que só excepcionalmente tivemos um sistema administrativo e um corpo de funcionários puramente dedicados a interesses objetivos e fundados nesses interesses. Ao contrário, é possível acompanhar, ao longo de nossa história, o predomínio constante das vontades particulares que encontram seu ambiente próprio em circuitos fechados e poucos acessíveis a uma ordenação impessoal... (Holanda, 1995, p. 146) 
A tradição culturalista, com colaborações de outros autores como Raimundo Faoro (1984) e Roberto DaMatta $(1981 ; 1991)$, atuou na formação de um mito da brasilidade que nos descreve com traços pré-modernos. Somos marcadamente emotivos, herdamos o personalismo da sociedade portuguesa e obedecemos às preferências do sentimento. Nessa sociedade, atua o imaterial, não o material; vale mais o contextual que o contratual, o que inevitavelmente faz prevalecer, de acordo com essa visão, os interesses pessoais, a corrupção e a perversidade. Souza (2015) considera que essa gramática social tornou-se uma segunda natureza, que, por alcançar essa condição, é automaticamente legitimada e se torna inacessível à crítica. Uma das formas de naturalização dessas noções é a reiteração delas na cultura midiática, da telenovela ao jornal diário - o qual, muitas vezes, evoca a inteligência culturalista brasileira na condição de autoridade para afirmar, com bases pretensamente científicas, o que é já senso comum.

\section{"Exércitos simbólicos"}

Para Jessé Souza, no processo de construção de uma ideia-força, o que é produzido no meio acadêmico, articulado a interesses de forças dominantes, naturaliza-se no senso comum. Como dito, a propagação de uma ideia-força depende em grande parte de narrativas midiáticas, como as da telenovela, do cinema, das revistas e dos telejornais, exemplos citados pelo autor.

Como Jessé Souza deixa claro em A ralé brasileira, seu pensamento é afinado com o da teoria crítica, expresso em Dialética do esclarecimento, de Adorno e Horkheimer. Para Souza (2018b, p. 57), as relações entre indústria cultural e públicos são marcadas, em todas as dimensões, pelo "consumo acrítico de ilusões pré-fabricadas".

A indústria cultural, segundo Souza, transformou em commodity uma das fontes morais da modernidade: a individualidade sensível (a outra seria o trabalho). A ascensão dos sentimentos (a noção de amor, a vida afetiva, a autenticidade) como aspectos orientadores de conduta e ações dos sujeitos foi uma revolução expressiva das elites artísticas e intelectuais do século XVIII que redefiniu valores da sociedade (Inglis, 2012). Inicialmente, essa fonte é plasmada na literatura romântica para, posteriormente, tornar-se base da indústria cultural. Para Jessé Souza (2018a, p. 53), "o que deveria ser uma aventura da autodescoberta individual acaba por virar mercadoria massificada ...", e, portanto, é desprovida de elementos emancipatórios.

A imaginação melodramática que estrutura esses produtos é tomada por Jessé Souza como redutora, pois propõe esquemas fixos para o entendimento do mundo. A mídia hegemônica opera por meio de binarismos, o que demoniza alguns indivíduos e heroiciza outros, como se viu na cobertura jornalística seletiva da corrupção no Brasil nos anos recentes. Souza (2018c) aponta na mídia hegemônica e em seu caráter melodramático elementos fundantes dessa infantilização e incapacidade de reflexão. "Este é o mundo das novelas, dos romances best-sellers recheados de clichês, dos telejornais da Rede Globo, dos programas de rádio patrocinados por bancos etc." (Souza, 2018c, p. 59).

Esse binarismo garante, ainda, de modo mais processual, a propagação de aspectos "racistas do culturalismo dominante", em que se idealiza o estadunidense como "branco", "protestante" e superior moral e economicamente ao brasileiro vira-lata. E conclui: "A viralatice brasileira sobrevive por conta dessa visão míope e rasteira do mundo, reproduzida por universidades, escolas, TVs e jornais" (Souza, 2018c, p. 47).

Parte da população brasileira está, portanto, submetida a essas mídias dominantes:

Uma imprensa manipuladora e hipócrita, como a brasileira, uma indústria cultural antirreflexiva e concepções de mundos hegemônicas e subservientes ao poder de fato são os atuais exércitos simbólicos que mantêm submissa a sociedade e bloqueiam seu potencial de desenvolvimento humano. (Souza, 2018a, p. 25)

A expressão "exércitos simbólicos" integra um campo semântico utilizado por Jessé Souza que designa as muitas batalhas sociais no Brasil. Frações da classe média são denominadas, pelo autor, de "tropa de choque" das verdadeiras elites 
${ }^{2} \mathrm{~A}$ instrumentalização do noticiário desse período foi analisada discursivamente em trabalhos como o de Mario Viggiano (2019, p. 200), que demonstra como jornais brasileiros ditos de referência, por meio do infotenimento e da articulação entre matérias e anúncios publicitários, subverteram o conteúdo informativo com opinião "cada vez mais indisfarçada". Segundo o autor, houve "estruturação de discursos de cunho ofensivo e pejorativo para desacreditar, enfraquecer e pedir a saída da presidente Dilma do governo" (Viggiano, 2019, p. 201). Viggiano (2019, p. 38) compreende a instrumentalização como a manipulação do noticiário para "priorizar interesses específicos e ... mobilizar a opinião pública em determinada direção".

\footnotetext{
${ }^{3}$ As frases de Jessé Souza referentes ao
} filme Coringa foram retiradas desse vídeo. econômicas - o 1\% endinheirado do Brasil. A tropa defende essa elite em "tribunais, na sala de aula, nos jornais e em todas as dimensões do cotidiano". Passou a combater por ela nas ruas, como em junho de 2013, "sequestrando as demandas populares do início das manifestações em nome da eterna corrupção só da política - para defender os interesses da classe de endinheirados que as explora" (Souza, 2015, p. 249).

Dentro da produção midiática, Souza apreende o jornalismo como correia de transmissão, pois “apenas distribui informações e opiniões" (Souza, 2018c, p. 113). As ideias propagadas pela imprensa são produzidas fora dela, por intelectuais que possuem "o prestígio e a formação para tanto" (Souza, 2018c, p. 113). Daí emerge a importância de compreender a formação do pensamento social brasileiro e os interesses subjacentes a ele. A imprensa atua com diferentes prazos: na sedimentação mais lenta das ideias conservadoras, em que se incluem as do liberalismo hegemônico, e no estímulo à ação mais rápida, a partir do modo como medeia os acontecimentos durante as crises. Como Souza (2016) afirma em Radiografia do golpe, o jornalismo hegemônico foi decisivo na captura das jornadas de 2013. Aos poucos, as manifestações foram federalizadas na cobertura jornalística para atingir o governo de Dilma Rousseff. Entre 2013 e 2016, a mídia "fulanizou a corrupção", concentrada no Estado, e tornou o combate a ela um espetáculo, o que propiciou “a manipulação perfeita do público cativo" (Souza, 2016, p. 88)².

Conclui-se que, para Jessé Souza, a mídia é redutora da complexidade do cotidiano e atua a favor das elites financeiras. Ela reverbera e naturaliza aspectos do mito nacional, que é forjado fora dela por parte da inteligência brasileira. A comunicação midiática constitui-se de narrativas jornalísticas e de outros âmbitos, como os da publicidade e do entretenimento. Muitas narrativas do entretenimento são produtos de dupla face, como a telenovela brasileira e sua orientação para o debate mais direto de elementos sociais, ou, ainda, para mencionarmos um exemplo específico, narrativas à la clef, como O mecanismo (2018), do serviço de streaming Netflix, que transformou a Lava Jato em série policial. O jornalismo corporativo, especificamente, é manipulador, no sentido de que maneja informação para compor narrativas que naturalizem o culturalismo conservador. As relações com as audiências são do campo dos efeitos, pois trata-se de indivíduos também manipuláveis.

\section{A complexidade das mediações}

A partir dos estudos de comunicação, notadamente aqueles referentes aos estudos culturais e de mediação, é possível abrir reflexões acerca tanto da unidade da indústria cultural, como da imposição de significados às audiências por meio de textos midiáticos.

A crítica política que o próprio Jessé Souza fez do filme estadunidense Coringa (2019) em seu canal do YouTube (https://bit.ly/3grk10u) ${ }^{3}$ ajuda-nos a desconstruir o primeiro aspecto acerca do caráter monolítico da mídia dominante, pois demonstra que a indústria do entretenimento é capaz de produzir narrativas com algum nível de provocação. Para Souza, o filme é montado para humanizar o Coringa, indivíduo espoliado, que sofre abusos nas relações sociais em geral. Construiu-se personagem com núcleo familiar, o que facultou a simpatia do espectador e impediu que o medo da personagem se sobrepusesse à reflexão. Para Souza, “a vida do joker é semelhante à metade da vida dos brasileiros que nascem em condições semelhantes". São vidas produzidas em sociedades desiguais como a brasileira e a estadunidense.

Como Souza conclui, "o doente não é a pessoa, mas [doentes são] as sociedades construídas para destruir as pessoas". Essas sociedades, como a Gotham City (espelho de Nova lorque, na virada da década de 1980) de Coringa, são marcadas pela ausência de vínculos solidários. Apontando para o início da era Reagan, nos Estados Unidos, Coringa é uma narrativa também sobre a ascensão das políticas neoliberais, caracterizadas, novamente de acordo com Dardot e Laval (2016, p. 329), "pela "diminuição das proteções e das solidariedades coletivas ...".

Essas sociedades são, segundo Jessé Souza, obstáculos ao reconhecimento. Assim, Coringa constrói a autoestima e a autoconfiança na violência, em atos em que ele se 
vê digno de deferência. A precariedade experimentada por muitos é o que impulsiona a luta coletiva, disparada pela violência do Coringa, ainda que a personagem negue reiteradamente que seu gesto seja político. Jessé Souza faz uma leitura (política, ele enfatiza) do filme fundamentada na teoria de Axel Honneth (2003), já acionada em $A$ ralé brasileira para interpretar os dados empíricos que mostram as lesões afetivas sofridas pela classe.

O fato de Jessé Souza estabelecer, na leitura do filme, relações producentes entre signo e sociedade não faz, contudo, com que seu pensamento mais geral desafie a noção monolítica da indústria cultural, o que pode impedir o avanço na discussão acerca dos produtos midiáticos. Porém, convém pontuar dois aspectos da intervenção de Jessé Souza no YouTube: a produção de um canal nesse meio indica que o sociólogo constata a insuficiência da cultura do livro e daquela dos circuitos acadêmicos mais tradicionais para o debate transformativo da sociedade, pelo menos de forma mais imediata. Essa insuficiência do livro persiste mesmo que o projeto de Jessé Souza na literatura social seja o de interagir com um público mais alargado, objetivo atingido pelo autor, dada a circulação de suas obras. Portanto, as mídias sociais são, hoje, importante lugar de consolidação de ideias-forças, para além das mídias dominantes criticadas por Jessé Souza em sua obra.

Segundo, é preciso ressaltar as questões que uma obra como Coringa, produzida no centro da indústria do entretenimento, traz para o debate social. As pessoas querem discutir aquilo a que assistem e, como demonstrou uma das experiências que contribuíram para os Estudos Culturais, desejam relacionar as narrativas a suas situações de vida (Williams, 2011). Muitos produtos midiáticos são conservadores, mas também mais ambíguos do que determinada teoria crítica admitiria. Essa abordagem só pode ser empreendida, no entanto, se deixarmos de lado a concepção de que a ficção popular é necessariamente forma de controle e ameaça à autonomia dos sujeitos.

Para Jessé Souza, como vimos, os enquadramentos e representações midiáticas "fazem a cabeça" de indivíduos passivos e incautos. O pensamento da comunicação como processo de mão única talvez persista porque a ideia de massa, que faz ponte entre ciências sociais e comunicação, permanece ativa nos dois campos. No final da década de 1950, Raymond Williams (2015) já nos advertia quanto à nocividade do termo "massa" não somente por ele trazer uma forma equivocada e preconceituosa de se referir às classes populares, mas por ter se tornado um pressuposto comunicacional.

Na comunicação, massa tornou-se, no século XX, palavra mais corrente do que broadcast para nomear um tipo de transmissão de larga escala que "criou divisões incomensuráveis entre o transmissor e a audiência" (Williams, 2015, p. 17). O termo já era usado no século XIX para substituir turba, que designava pejorativamente "os outros, o desconhecido, os sujos, a multidão que não me inclui" (Williams, 2015, p. 17). Tomado como massa, o público anônimo dos meios de comunicação é descrito como conjunto de indivíduos sem capacidade crítica e de gostos e hábitos vulgares. Essa projeção de público estabeleceu-se como fórmula para a chamada comunicação de massa. Isso é, os produtores adotaram a visão rebaixada das audiências e desenvolveram suas formas de contato a partir dela. Mas, para Williams (2015, p. 20), "as massas não existem de fato, o que existem são modos de ver pessoas como massa".

Os estudos de teoria literária e de recepção contribuíram para construir uma visão emancipada do leitor, reconhecendo o caráter desiderativo da leitura e que esta pode ser abusiva, pois não há lei que determine o modo como se deve ler (Eco, 1994). Os estudos de mediação acrescentaram uma importante camada à produção de sentido: as instâncias de sociabilidade. Quando Martín-Barbero (1997, p. 281) escreve que devemos deslocar o "espaço de interesse dos meios para o lugar onde é produzido o sentido", ele se refere às redes do cotidiano que atuam entre o âmbito privado e o universo público da cidade. Podemos, hoje, pensar nesses núcleos ainda de forma tradicional, como as quadras de esporte, a sala de aula, os cineclubes, as associações de bairro e a igreja, mas também a partir das redes sociais - os grupos de WhatsApp, por exemplo - e suas bolhas sem espaço para contra-argumentação ou debate. Os textos midiáticos circulam nesses ambientes, 
mais ou menos tradicionais, mais ou menos solidários, que atuam como mediadores. Para usar uma metáfora de Carlo Ginzburg (1998), apropriada por Martín-Barbero, essas instâncias são uma "peneira", a partir da qual alguns aspectos são colocados em relevo e outros são relevados ou mesmo ocultos na leitura dos sujeitos. Não se pode compreender os usos de um texto sem compreender as instâncias de sociabilidade em que eles são mediados, nem sempre de forma coerente.

A pesquisa que investigou, em 2016, a concordância da população carioca com o bordão "bandido bom é bandido morto" levanta dados para pensarmos a mediação (Lemgruber et al., 2017). Nesse estudo, os autores discutem o peso da mídia na disseminação da "ideologia do justiçamento" e na perpetuação do paradigma autoritário no país. Ressaltam que não apenas os programas televisivos explicitamente policiais estão envolvidos no processo, mas também aqueles de entretenimento geral e o noticiário cotidiano. Na última década, as mídias sociais integraram essa circulação midiática, pois também propagam imagens violentas e estereótipos. A mídia dominante, segundo os autores, contribui para a cultura da vingança por meio de diversos artifícios, como o de demonizar bandidos (ou sujeitos assim identificados) e o de fazer uso da linguagem do afeto (que privilegia o medo, a raiva, a repulsa e o ódio) e da narrativa instantânea (de apreensão fácil e simplificadora do debate de segurança pública).

A pesquisa enfatiza, contudo, o fato de evangélicos praticantes "serem os mais avessos à aceitação da morte como solução para os problemas de segurança" (Lemgruber et al., 2017, p. 65). Logo, ainda que estejam em contato com as narrativas midiáticas, esses indivíduos são os que mais repudiam a frase "bandido bom é bandido morto". Em suas conclusões, o relatório retoma esse dado e o aponta como significativo para se pensar caminhos para o "contraponto à cultura da execução". Segundo eles, a prática religiosa, como instância de sociabilidade, pode funcionar como "freio à barbárie". Ainda que essas relações sejam instáveis e nem sempre facilmente compreensíveis, observa-se, no relatório, a importância da mediação na propagação ou do repúdio ao imaginário "monopolizado" pela mídia, para usarmos expressão dos autores.

Silverstone (2002) aponta que indivíduos podem acatar os significados dominantes não porque são manipulados midiaticamente, mas porque lhes convém. Segundo ele, a vida diária é dura para a maioria das pessoas e, nela, ambiguidades são vistas como ameaças, não como complexidades producentes. "O paradoxo, assim como a história, é um luxo das elites" (Silverstone, 2002, p. 763). As mídias oferecem, por meio de seus esquemas simplificadores, orientações para a vida cotidiana que podem proporcionar "um certo grau de conforto" (Silverstone, 2002, p. 764). Chegamos, assim, a relações entre indivíduos e textos midiáticos que são baseadas em cumplicidade (quando as pessoas se eximem de criticar as mediações e as aceitam numa lógica de jogo) e conluio (quando as pessoas tiram proveito dessas mediações). A ideia de manipulação não é suficiente para compreender determinados laços de conivência entre mídia e sociedade ${ }^{4}$.

${ }^{4}$ Ver também entrevista de Sílvia Viana (https://bit.ly/3iMyDtw), que considera a possibilidade de a própria racionalidade neoliberal ser uma forma de mediação mais ampla, que fez com que determinados grupos acatassem, de modo conivente e pouco questionador, a cobertura da imprensa nos anos que antecederam o impeachment de Dilma Rousseff. Nessa entrevista, Viana critica a ideia de manipulação e refere-se à percepção geral de que a condição de manipulado é sempre imputada ao outro, nunca ao próprio sujeito que acusa.

\section{Considerações finais}

Neste artigo, buscou-se, a partir dos estudos de comunicação, contribuir com uma abordagem da crítica ao culturalismo conservador atenta à complexidade dos processos de mediação. Concordamos com a ideia de Jessé Souza de que a compreensão da formação do mito de brasilidade e dos interesses articulados a ele é importante para se produzir reflexões acerca de nosso imaginário social e, assim, desnaturalizar aspectos de nossa desigualdade social.

A cultura midiática, bem como suas narrativas e representações, são importantes para a cristalização da ideia-força identificada por Souza. A mídia dominante não é um campo neutro, pois possui seus próprios interesses submetidos à racionalidade neoliberal. No entanto, a mídia é também mais porosa do que a tese de unidade da indústria cultural prevê, ainda que determinados contextos nos façam retomar o vocabulário da manipulação - de informação e das audiências. Pelo menos dois aspectos contribuem para a compreensão dessa lógica: primeiramente o de que a mediação é, de fato, assimétrica, no sentido de que nem todos os espectadores, 
ainda que não mancomunados com a mídia, possuem a mesma capacidade de contestar os significados dominantes (Silverstone, 2002). Em segundo lugar, a cobertura midiática é recorrentemente instrumentalizada, por meio do que Perseu Abramo (2016) descreveu como padrões de manipulação da informação que resultam, segundo ele, na manipulação da própria realidade.

Mas se os significados hegemônicos produzidos e postos em circulação nessa mídia possuem força de penetração, permanece a questão da forma desigual como aderem à sociedade. Se o receptor é de fato ativo, devemos compreender melhor como se dá sua produção de sentido: as negociações que são feitas nas audiências ou mesmo as relações de cumplicidade estabelecidas entre os públicos e as narrativas midiáticas do jornalismo e do entretenimento. Logo, as instâncias de sociabilidade são lugares de investigação privilegiados, para o estudo tanto das interações com a mídia dominante, como das interações nas mídias sociais.

Demanda-se, também, compreender como emergem os procedimentos de questionamento dos significados dominantes. Assim, pode-se buscar estratégias para que a capacidade crítica seja melhor distribuída socialmente. É também possível mapear outras narrativas midiáticas em que os elementos centrais do culturalismo conservador são confrontados, seja por meio do desnudamento de nossos conflitos sociais ou da afirmação de experiências solidárias, na proposição de outros imaginários para nossa sociedade.

\section{Referências}

ABRAMO, P. (2016). Padrões de manipulação na grande imprensa. Fundação Perseu Abramo.

DAMATTA, R. (1981). Carnavais, malandros e heróis. Zahar.

DAMATTA, R. (1991). A casa e a rua. Guanabara Koogan.

DARDOT, P.; \& LAVAL, C. (2016). A nova razão do mundo. Boitempo.

ECO, U. (1994). Seis passeios pelos bosques da fiç̧ão. Companhia das Letras.

FAORO, R. (1984). Os donos do poder. Globo.

FREYRE, G. (1990). Casa-grande \& senzala. Record.

GINZBURG, C. (1998). O queijo e os vermes. Companhia das Letras.

HOLANDA, S. B. (1995). Raízes do Brasil. Companhia das Letras.

HONNETH, A. (2003). Luta por reconhecimento. 34.

INGLIS, F. (2012). Breve história das celebridades. Versal.

LEMGRUBER, J; CANO, I.; \& MUSUMECI, L. (2017). Olho por olho? O que pensam os cariocas sobre "bandido bom é bandido morto". Cesec.

MARTíN-BARBERO, J. (1997). Dos meios às mediações. Ed. UFRJ.

SERELLE, M. (2018). O culturalismo conservador em Narcos. Comunicação, mídia e consumo, 15(42), 118-137. http://dx.doi.org/10.18568/cmc.v15i42.1495

SILVERSTONE, R. (2002). Complicity and collusion in the mediation of everyday life. New Literary History. 33(4), 761-780. http://dx.doi.org/10.1353/nlh.2002.0045

SOUZA, J. (2000). A modernização seletiva. Ed. UNB. 
SOUZA, J. (2015). A tolice da inteligência brasileira. Leya.

SOUZA, J. (2012). Os batalhadores brasileiros. Editora UFMG.

SOUZA, J. (2016). A radiografia do golpe. Leya.

SOUZA, J. (2018a). A classe média no espelho. Estação Brasil.

SOUZA, J. (2018b). A ralé brasileira (3ạ. ed.). Contracorrente.

SOUZA, J. (2018c). Subcidadania brasileira. Leya.

TAYLOR, C. (2004). Modern social imaginaries. Duke University Press.

VIGGIANO, M. F. I. (2019). O golpe midiático no golpe: o discurso de instrumentalização nos jornais Folha de S.Paulo, O Globo e O Tempo e o impeachment da presidente Dilma Rousseff (Tese de doutorado, Pontifícia Universidade Católica de Minas Gerais). Biblioeteca Digital de Teses Dissertações da PUC-Minas. http://www.biblioteca. pucminas.br/teses/Letras_MarioFranciscolanniViggiano_7830.pdf

WILLIAMS, R. (2011). O futuro dos Estudos Culturais. In R. Williams, Política do modernismo (pp. 171-187). Editora Unesp.

WILLIAMS, R. (2015). A cultura é algo comum. In R. Williams, Recursos da esperança (pp. 3-28). Editora Unesp.

\section{Obras audiovisuais}

PADILHA, J., PRADO, M. (Produtores Executivos). (2018-presente). O mecanismo [Série de TV]. Netflix.

TODD, P. (Diretor). (2019). Coringa. [Filme]. Warner Bros. Pictures. 